\title{
How do Markets Manage Water Resources? An Experiment
}

\author{
Aurora García-Gallego \\ LEE, Department of Economics, Universitat Jaume I (Castellón-Spain) \\ (mgarcia@uji.es) \\ Nikolaos Georgantzís \\ Universidad de Granada and LEE Universitat Jaume I \\ (ngeorgantzis@ugr.es) \\ Roberto Hernán \\ Department of Economics, Universidad Europea de Madrid \\ (Roberto.Hernangonzalez@gmail.com) \\ Praveen Kujal \\ Department of Economics, Universidad Carlos III, Calle Madrid 126, Madrid 28903, \\ Spain \\ (kujal@eco.uc3m.es)
}

\begin{abstract}
We experimentally test how a private monopoly, a duopoly and a public monopoly allocate water of differing qualities to households and farmers. Most of our results are in line with the theoretical predictions. Overexploitation of the resources is observed independently of the market structure. Stock depletion for the public monopoly is the fastest, followed by the private duopoly and private monopoly. On the positive aspects of centralized public management, we find that the average quality to price ratio offered by the public monopoly is substantially higher than that offered by the private monopoly or duopoly.
\end{abstract}

Keywords: Resource overexploitation, private and public monopoly, duopoly, water quality, experiments. 


\section{Introduction}

Countries all over the world are increasingly aware that efficiency in water allocation is very important. The growing demand ${ }^{1}$ on water resources and the broadly debated climate change are among the main reasons why water management is becoming an important issue. For example, The Economist drew attention towards the impending water crisis in China. ${ }^{2}$ Some of the main problems in China have been due to bad management, pollution and pricing of water below cost. Thus, it is now well accepted by policy makers that allocating water within the existing allocation mechanisms is often inefficient. The need for market-based mechanisms in water management has been gaining acceptance in various forums. ${ }^{3}$ In its 1993 policy paper (Water Resources Management), the World Bank states that the deterioration and scarcity of fresh water in recent times is due to the "...failure to properly consider the economic value of water. Given that water is given little or no economic value it is misallocated and misused". However, the extraction process is not the only concern of the authorities involved. In recent years, an increasing number of city councils around the world use recycled water for drinking ${ }^{4}$, mixing streams that feed into reservoirs ${ }^{5}$ or injecting recycled water into ground aquifers. In Australia, with its scarce water resources, water recycling is now set to play a much greater part in the water management cycle. ${ }^{6}$ Thus, the quality resulting from the mixture of different types of water under different institutional settings is an important issue which has received scant attention so far.

In this paper we build a theoretical model and study experimentally how market structure affects the management of two different water resources ${ }^{7}$. We experimentally study how different market structures such as a private monopoly, a duopoly and public utility may affect water resource extraction and stock management. Furthermore, we assume that quality is endogenously determined from the mixture of different types of

\footnotetext{
${ }^{1}$ Recent estimates put the world water market at \$300-\$325 billion (see Water Pumps, 2008).

${ }^{2}$ See also Yang et al. 2003.

${ }^{3}$ Increasingly, cities (countries) are choosing the management and distribution of water resources through market mechanisms. Some recent examples include Aman (Jordan), Riyadh (Saudi Arabia) and Lezíria del Tajo (Portugal) (http://www.fcc.es/fcc/corp/esp/sdp_n_ddln_332.htm and http://www.cincodias.com/articulo/empresas/FCC/gana/macrocontrato/gestion/agua/Portugal/cdscdi/2006 0131cdscdiemp_10/Tes/).

${ }^{4}$ Orange County (U.S.) and Queensland (Australia) are recycling waste water.

${ }^{5}$ In Virginia (U.S.) recycled water is added to a stream feeding the Occoquan reservoir.

${ }^{6}$ The Australian Academy of Science, http://www.science.org.au/nova/095/095key.htm.

${ }^{7} \mathrm{We}$ abstract from the common pool resource problem which has been dealt with in other papers like Walker et al. 1990, Walker and Gardner 1992, Gardner et al. 1997 and Mason and Philips 1997.
} 
water. Market clears following a complex process based on block rate pricing and a smart mechanism, related to the one used in Murphy et al. 2000, enabling us to abstract from demand-side behaviour.

Increasingly, experimental methods are being applied to study alternative auctions, rules and market structures in a controlled environment at a reduced cost. Laboratory experiments are useful in providing valuable insights that can reduce the uncertainty associated with the implementation of new institutions (see Plott 1987). The usefulness of applying the experimental methodology lies in the fact that the laboratory can be a useful test bed to undertake a direct test of an existing market mechanism (Murphy et al. 2000, 2009 and Garrido 2007) or study some proposed new systems. To quote Smith 1976 (pp. 274-275), "Laboratory experience suggests that all of the characteristics of 'real world' behavior that we consider to be of primitive importance [...] arise naturally, indeed inevitably, in experimental settings. Furthermore, the process of experimental design forces one to articulate rules and procedures, the collection of which forms an institution, organization, or 'body of law' with striking 'real world' parallels" (cf. Shubik 1974). The strength of laboratory experiments lies in the fact that institutional rules and incentives are clearly defined. The fact that laboratory experiments are regularly used in the design of auction mechanisms for a broad spectrum of markets lends support to this argument. In that sense, the use of abstract and controlled settings serves similar objectives as does the use of subject pools recruited among university students. Both strategies help the experimenter study the interaction between market institutions and human nature in isolation from other confounding factors.

Murphy et al. 2000, Garrido 2007 and Murphy et al. 2009 are good examples of the use of experimental methodology in studying questions arising out of specific problems associated with water allocation. Murphy et al. 2000 argue that making substantial institutional changes in water systems is cumbersome due to the cost of implementing a system and its irreversibility. They use a "smart" ${ }^{8}$ market to study water allocation problems in California. Their experiments show that efficiency increases when monopoly control over conveyance is replaced with co-tenancy. Garrido 2007, meanwhile, tests some of the measures adopted under the 1999 water reforms in Spain. Under this reform, junior right holders are not allowed to purchase water from senior

\footnotetext{
${ }^{8}$ In a 'smart' market the central program applies optimization algorithms to the submitted bid-offer messages to determine the prices and allocations that maximize the gains from exchange.
} 
users. Further, the law did not explicitly define water rights over unused water that carries over to the next season. His results show that defining water rights over saved units across periods increases the average stock levels of reservoirs, and reduces market price instability. Senior users are better off if they are allowed to trade their water rights and providing inter-temporal rights to users over unused water results in higher reservoir levels. Garrido 2007 shows that the changes in the water law resulted in effects that were opposite to those desired by the policy makers. Meanwhile, Murphy et al. 2009 test three different water market institutions ${ }^{9}$ incorporating instream flow values into the allocation mechanism through active participation of an environmental trader. They find that direct environmental participation in the market can achieve efficient and stable outcomes.

In our analysis, market structure is relevant since, although water is generally managed by state owned public utilities that are involved in the extraction and management of water resources, other management regimes are also possible. The three market structures studied here are chosen to reflect the public management status quo and two alternative scenarios of privatization, a monopoly and a duopoly one. Rather than restricting our analysis to extraction issues, we analyze water quality as the result of mixing water from two different water resources. ${ }^{10}$ Given that potable water should satisfy some minimum standards, we introduce a costly purification process which is automatically activated to keep water quality up to the required minimum. ${ }^{11}$

In our theoretical framework, extraction efficiency is achieved as long as stocks are kept as high and, thus, extraction costs as low as possible. In fact, sufficiently caring for future extraction efficiency will force a decision maker to maintain maximal stocks. However, towards the final periods of a finite horizon problem, a social planner managing a public utility will prefer to intensify extraction beyond this level. This is because the vanishing benefits of future extraction efficiency are offset by the present benefits from supplying more water to the users. On the contrary, a private monopolist will keep stocks at maximal level, although this will be achieved at the cost of lower

\footnotetext{
${ }^{9}$ The three different property right regimes are: (1) Minimum instream flow constraints without active participation of instream flow interests; (2) No instream flow rights, but instream flow demands can be met by subsidizing downstream consumption; and (3) Private property rights to instream flow.

${ }^{10}$ Quality concerns arise when mixing water. For example, residents of the city of Toowoomba in SouthEast Queensland rejected a scheme to recycle sewage to top up drinking supplies.

${ }^{11}$ Though generally irrigation water is not purified, there could be situations where this is the case (as suggested by a reviewer, farm water could have a threshold too). In order to simplify the analysis, we do not enter into this issue in this paper, assuming that water quality cannot fall below acceptable levels for irrigation.
} 
output sold to the users. Thus, compared to steady state social welfare maximization, inefficiencies may arise either due to an inefficient extraction path or due to the exercise of monopoly power. Also, given that the social planner's payoffs depend also on consumer satisfaction from quality, a public utility should supply the highest water qualities. Our experimental results largely confirm the predicted ranking of stocks, quantities and quality-to-price ratios under public and private management of the resources, placing a private duopolistic structure between these two extremes. Nevertheless, inefficiently intense extraction appears to be a common and persistent error in the three structures leading to systematic deviation from the predicted paths

The paper is structured as follows. In Section 2 we explain the theoretical model. In Section 3 we describe the experimental design. Section 4 discusses the experimental results. Section 5 concludes. The mathematical details of the model and the instructions for experimental subjects are included in the Appendix.

\section{The theoretical framework}

There are two renewable stocks $S_{H}$ (high quality stock) and $S_{L}$ (low quality stock) from which water may be extracted. For the sake of simplicity, we assume that the recharge to the respective basin is deterministic and constant and is given by $a_{H}=a_{L}$. Further, once the maximum storable stock, $S_{H}^{\max }=S_{L}^{\max }$, is reached, extra water inflow is lost at no private or social cost or benefit. The return flow of consumed water is assumed to be negligible. Thus, changes in stocks are exclusively due to extraction and recharge. Extraction costs are supposed to be twice differentiable functions of quantity and stock size. First derivatives are assumed to be, respectively, positive and negative, whereas second derivatives are positive.

Water resources differ in qualities. Quality of water in an aquifer may be lower due to marine intrusion, or due to infiltration of fertilizer from agriculture. Let the qualities be denoted respectively by $Q_{H}$ and $Q_{L}$, where $Q_{H}>Q_{L}>0$. The two qualities are assumed to be constant over time. However, any intermediate quality may be supplied to the consumers as a result of mixing water from the two sources. Note that strategic quality choice is usually studied in the context of two stage product differentiation models, many of which belong to a strand initiated by Mussa and Rosen $1978 .{ }^{12}$ In these

\footnotetext{
${ }^{12}$ For a recent contribution and review of this literature, see García-Gallego and Georgantzís 2009.
} 
models, product quality is strategically chosen taking into account the competitionreducing effect of product differentiation. ${ }^{13}$ Thus, quality choice determines the fierceness of price competition. In our paper, the causality is reversed. Final product quality is the result rather than the cause of price setting behaviour.

Mixing quantities $K_{H}$ and $K_{L}$ of the two qualities results in water whose quality is given by the weighted average:

$$
Q_{M}\left(K_{H}, K_{L}, Q_{H}, Q_{L}\right)=\frac{K_{H} Q_{H}+K_{L} Q_{L}}{K_{H}+K_{L}}
$$

Resource flow between the sources and the consumers is coordinated by a pair of knots that centralize the mixing process at the consumer's location. Figure 1 helps us visualize the structure of the pipeline network considered.

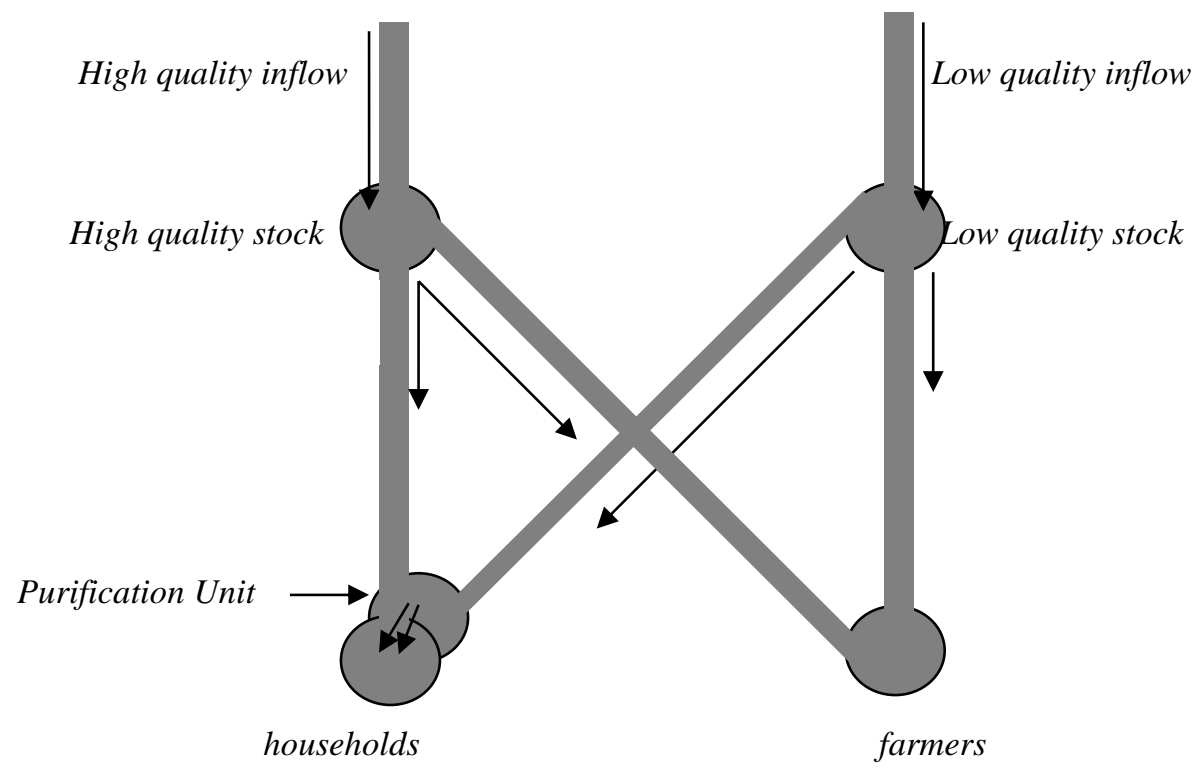

Figure 1. The pipeline network.

Suppose that the behaviour of the consumers can be aggregated under one of two types: i) households $(h)$, and ii) farmers $(f)$. Consumers differ in their respective preferences regarding the quality of water. Both types prefer a higher quality, and quantity of the water to a lower one. Households consume water whose quality weakly

\footnotetext{
${ }^{13}$ This is also the theme of an alternative approach by Sucked and Sutton 1982.
} 
exceeds a minimum standard. If mixed quality does not satisfy this condition, it will be subject to purification. Formally, the quality of potable water should weakly exceed a constant minimum quality standard $Q_{\min }$ where $Q_{H}>Q_{\min }>Q_{L}$. Mixed water of quality $Q_{M}$ may, or may not, satisfy the minimum quality standard. This depends on the quantities and qualities mixed.

Quality may be improved at a cost. This cost is an increasing function of the difference between the quality before and after purification. Moreover, a given improvement $\Delta Q$ of a lower quality is less costly than the same improvement performed on a higher quality. Let the initial quality subject to purification be $Q_{0}$. The purification cost, denoted by $C_{\Delta Q}\left(K, \Delta Q, Q_{0}\right)$, for a certain water quality $Q_{0}$ and quantity $K=K_{H}+K_{L}$ requiring a quality improvement $\Delta Q$, is assumed to satisfy the following conditions:

$$
\frac{\partial C_{\Delta Q}}{\partial K}>0, \frac{\partial^{2} C_{\Delta Q}}{\partial K^{2}}>0, \frac{\partial C_{\Delta Q}}{\partial \Delta Q}>0, \frac{\partial^{2} C_{\Delta Q}}{\partial(\Delta Q)^{2}}>0,\left.\frac{\partial C_{\Delta Q}}{\partial Q_{0}}\right|_{\Delta Q}>0,\left.\frac{\partial^{2} C_{\Delta Q}}{\partial Q_{0}^{2}}\right|_{\Delta Q}>0
$$

The specific formulation adopted here is provided in Appendix A. The purification procedure is assumed to be costly enough such that it is not profitable to improve quality above the minimum standard. Hence, the quality consumed by households is the maximum between the minimum potable quality, and the mixed quality without purification. Thus, $Q_{0}=Q_{M}$ and the optimal quality improvement is:

$$
\Delta Q=\left\{\begin{array}{l}
Q_{\min }-Q_{M} \quad \text { if } \quad Q_{\min }>Q_{M} \\
0 \text { if } \quad Q_{\min } \leq Q_{M}
\end{array}\right.
$$

Further, assume that the utility functions for the two consumer types are, respectively, $U_{h}=U_{h}\left(K_{h}, Q_{M h}\right)$ and $U_{f}=U_{f}\left(K_{f}, Q_{M f}\right)$ (where $K_{h}=K_{H h}+K_{L h}$ and $\left.K_{f}=K_{H f}+K_{L f}\right)$. The specification used here is twice differentiable in both quality and quantity and is provided in Appendix A. Farmers' utility is increasing in both arguments. While depending on the purification cost function, the utility function of households might be increasing in the quantity of low quality only up to a certain $\operatorname{limit}^{14}$. From twice differentiability of the utility functions it follows that the sum of the functions is twice differentiable too. Our assumptions concerning consumer utility are qualitatively similar to those in Gjerstad et al. 2000, on multiple commodities that are interdependent in consumption.

\footnotetext{
${ }^{14}$ In fact, it will be increasing if mixed quality weakly exceeds the minimum quality standard.
} 
Following a standard formulation of similar groundwater extraction problems, a lower stock implies higher extraction costs. We define $C_{i}\left(S_{i}, K_{i}\right)$ as the extraction costs of $K_{i}$ units from a given stock level $S_{i}$, for $i=H, L$. Thus, each period's unit extraction cost and past levels of extraction are positively correlated. Furthermore, we assume that the extraction of the first five units from a stock at full capacity is costless. We will call stock levels between 16 and 20 units the efficient extraction stock levels or simply costless extraction stock levels. The specific correspondence between stock levels and extraction costs used here is provided in the table of extraction costs in Appendix B.

The indirect social welfare function $V\left(K_{H}, K_{L}\right)$, which maximizes instantaneous consumer surplus for a given quantity of water, can be obtained as a solution to the following problem:

$$
\begin{aligned}
& V\left(K_{H}, K_{L}\right)=\max _{K_{H h}, K_{H f}, K_{L f}, K_{L h}} U_{h}\left(K_{H h}, K_{L h}, Q_{M h} ; K_{H}, K_{L}\right)+U_{F}\left(K_{H f}, K_{L f}, Q_{M f} ; K_{H}, K_{L}\right) \\
& \text { s.t. } \\
& \text { (i) } K_{H}=K_{H h}+K_{H f} \\
& \text { (ii) } K_{L}=K_{L h}+K_{L f} \\
& \text { (iii) } Q_{M h}=\frac{Q_{H} K_{H h}+Q_{L} K_{L h}}{K_{H h}+K_{L h}} \\
& \text { (iv) } Q_{M f}=\frac{Q_{H} K_{H f}+Q_{L} K_{L f}}{K_{H f}+K_{L f}}
\end{aligned}
$$

For a given extraction policy by the managers of the resources, the allocation of different water qualities to the two types of consumers and the subsequent total consumption of each water type, is delegated to a "smart" downstream agent, acting according to the objective and restrictions of (3). This allows us to focus on the behavioural aspects of the supply side.

In the steady state, inequalities $K_{H} \leq a_{H}$ and $K_{L} \leq a_{L}$ must hold in order to guarantee the inter-temporal feasibility of the solution. Extraction patterns not satisfying these restrictions, lead to a gradual exhaustion of the resources. In fact, the equality corresponds to what we call the hydrological equilibrium of the system. In this equilibrium, the quantities consumed in each period are equal to the time-unit recharge of each resource. However, we will see that this hydrological equilibrium is not necessarily satisfied by all the theoretical benchmarks considered. This is the case for our private profit seeking monopoly benchmark, in which the firm finds it profitable to 
sell less than the maximum feasible quantity, yielding under-extraction of the resource. On the other extreme, a finite-horizon social planner will tend to extract more than that implied by this benchmark towards the end of its extraction period because the concern of future extraction efficiency vanishes, while surplus maximization persists.

In order to address social optimality, we consider the benchmark case of a social planner, discounting future total wealth by $\delta$, maximizing the present value of social welfare over an infinite horizon, as indicated by:

$$
\begin{aligned}
& \max _{K_{H t}, K_{L t}} \int_{t_{0}}^{\infty} e^{-\delta t}\left[V\left(K_{H t}, K_{L t}\right)-C_{H t}\left(S_{H t}, K_{H t}\right)-C_{L t}\left(S_{L t}, K_{L t}\right)\right] d t \\
& \text { s.t. } \\
& \text { (i) } \frac{d S_{H t}}{d t}=\left\{\begin{array}{cc}
-K_{H t}+a_{H} & \text { if } S_{H}<S_{H}^{\max } \\
0 & \text { if } S_{H}=S_{H}^{\max }
\end{array}\right. \\
& \text { (ii) } \frac{d S_{L t}}{d t}=\left\{\begin{array}{cl}
-K_{L t}+a_{L} & \text { if } S_{L}<S_{L}^{\text {max }} \\
0 & \text { if } S_{L}=S_{L}^{\text {max }}
\end{array}\right. \\
& \text { (iii) } S_{H t_{0}}=S_{H}{ }^{\max } \\
& \text { (iv) } S_{L t_{0}}=S_{L}^{\max }
\end{aligned}
$$

Without loss of generality, suppose that initially the resource stocks are in the natural hydrological equilibrium being equal to the upper bound of the storage capacity. The steady state conditions can be formulated as follows:

$$
\begin{aligned}
& \left.\frac{\partial V\left(K_{H}, K_{L}\right)}{\partial K_{H}}\right|_{\left(K_{H}, K_{L}\right)=\left(a_{H}, a_{L}\right)}-\left.\frac{\partial C_{H}\left(S_{H}, K_{H}\right)}{\partial K_{H}}\right|_{\left(K_{H}, K_{L}\right)=\left(a_{H}, a_{L}\right)}+\left.\frac{1}{\delta} \frac{\partial C_{H}\left(S_{H}, K_{H}\right)}{\partial S_{H}}\right|_{K_{H}=a_{H}}=0 \\
& \left.\frac{\partial V\left(K_{H}, K_{L}\right)}{\partial K_{L}}\right|_{\left(K_{H}, K_{L}\right)=\left(a_{H}, a_{L}\right)}-\left.\frac{\partial C_{L}\left(S_{L}, K_{L}\right)}{\partial K_{L}}\right|_{\left(K_{H}, K_{L}\right)=\left(a_{H}, a_{L}\right)}+\left.\frac{1}{\delta} \frac{\partial C_{L}\left(S_{L}, K_{L}\right)}{\partial S_{L}}\right|_{K_{L}=a_{L}}=0
\end{aligned}
$$

These conditions simultaneously determine the steady-state standing-stocks of $S_{H}$ and $S_{L}$. They state that, in the long run, the marginal social utility, which embodies the respective resource price in the economy, should equal the social costs of extraction represented on the right hand side. In each condition, the first term reflects the marginal 
social utility, whereas the other two terms correspond to the marginal cost that results from extracting a quantity $K_{H}\left(K_{L}\right)$ from the water stock $S_{H}\left(S_{L}\right)$.

Given that our objective is to test the model in the laboratory and in order to minimize the role of subjects' uncontrolled time preferences, we induce zero discounting by making a subject's earnings depend equally on all periods of a session. Thus, we focus here on a benevolent, infinitely living planner who cares equally for the welfare of both present and future generations. The planner will maximize efficiency in each period and will not sacrifice future efficiency in favour of higher present extraction as implied by (5). Thus, formally, in the special case of $\delta=0$, the conditions above become:

$$
\begin{aligned}
& \left.\frac{\partial C_{H}\left(S_{H}, K_{H}\right)}{\partial S_{H}}\right|_{K_{H} \leq a_{H}}=0 \\
& \left.\frac{\partial C_{L}\left(S_{L}, K_{L}\right)}{\partial S_{L}}\right|_{K_{L} \leq a_{L}}=0
\end{aligned}
$$

Given our formulation, the conditions in (6) imply that an infinitely living social planner should never let the stock levels fall to the point where extraction costs become positive, in order to implement the first-best solution. On the contrary, in a finite horizon context, the social planner would apply this rule only for an initial number of periods and would extract more than implied by this rule towards the last periods, because the increase in future extraction costs is bound and thus can be offset by the benefits of supplying more water to the users.

We set $a_{H}=a_{L}=3, S_{H}^{\max }=S_{H}^{\max }=20, Q_{L}=1, Q_{H}=5$ and $Q_{\min }=3$. Two features, which are rather specific to the dynamics of water stocks, are added to the structure: First, buyers are restricted to purchase up to 5 units of each type of water, given that their purchases in each period are used to serve their current needs. Second, given the constant inflow (recharge) in each period, the stock of water in the basins of each resource may increase, decrease or remain invariant depending on whether consumption is lower, higher or equal to the recharge rate. In all the scenarios considered below regarding the management of the resources, we assume that suppliers post a price schedule for the first five units of the water type they manage. Let $p_{i}=\left(p_{i 1}, \ldots, p_{i 5}\right)$ $i \in(H, L)$ be the price schedule submitted for water type $i$, where $p_{i}$ is a vector of the five minimum prices at which the decision maker is willing to sell each one of the five units he may sell to the market. We restrict each unit's price bid to weakly exceed the 
corresponding extraction cost and, given that extraction costs weakly increase as the stock decreases, we also impose that the price bid of the $n$th unit weakly exceeds the bid of the $(n-1)$ th one.

Given that prices are simply internal transfers from consumers to producers, there are various price pairs at which market clearing occurs at the socially optimal quantities and stocks. To understand this, we have to consider the price mechanism described above. The social planner has to set prices for each one of the five units that can be possibly sold into the market from each water quality. This type of pricing, also known as block pricing, is similar to simultaneous price/quantity-setting, because the decision-maker may set reasonable prices for, say, the first three units of each resource and then set prohibitively high price bids for the $4^{\text {th }}$ and $5^{\text {th }}$ unit, restricting consumption to three units, although such consumption may also occur for many different price schedules. Thus, the social planner can implement the hydrological equilibrium by any price vector yielding consumption of 3 units per resource, whereas prices for the $4^{\text {th }}$ and $5^{\text {th }}$ unit of each resource should be high enough to yield zero consumption beyond the third unit. As said above, in the steady state, stocks should be kept sufficiently high so that only costless extraction takes place. In other words, this implies that no unit should be extracted from stock levels below 15 units. In fact, given the discreteness of our design, there is an extraction path whose time average consumption achieves the hydrological equilibrium by alternating supplies of $\left(K_{H}, K_{L}\right)=(4,2)$ in one period and $\left(K_{H}, K_{L}\right)=(2,4)$ in the other, or vice-versa, that will yield higher payoffs than supplying the steady state hydrological equilibrium $\left(K_{H}, K_{L}\right)=(3,3)$. Furthermore, the public utility would also prefer to sell one unit more of any of the two products, at any period, without incurring higher extraction costs, as long as the stock before extraction is 20 or 19, so that extracting 4 units does not cause stocks to fall below the efficient extraction levels.

We are also interested in the solutions resulting from a centralized profit maximizing management of the two resources as well as a decentralized, non cooperative management by two competing profit-maximizing entities. First of all, observe that the cost-specific parts of the expressions in (5) are also valid in the private monopoly case, because the two types of water are extracted from separate basins, resulting in a separable cost function. Intuitively, this is a natural consequence of the fact that the stock level of one resource does not affect extraction costs specific to the 
other resource. Specifically, equilibrium for the private monopoly case is characterized by the condition:

$$
\begin{aligned}
& \frac{\partial R\left(p_{H}, p_{L}\right)}{\partial p_{H}}-\left[\frac{\partial C_{H}\left(S_{H}, K_{H}\right)}{\partial K_{H}}-\frac{1}{\delta} \frac{\partial C_{H}\left(S_{H}, K_{H}\right)}{\partial S_{H}}\right] \frac{\partial K_{H}\left(p_{H}, p_{L}\right)}{\partial p_{H}}-\left[\frac{\partial C_{L}\left(S_{L}, K_{L}\right)}{\partial K_{L}}-\frac{1}{\delta} \frac{\partial C_{L}\left(S_{L}, K_{L}\right)}{\partial S_{L}}\right] \frac{\partial K_{L}\left(p_{H}, p_{L}\right)}{\partial p_{H}}=0 \\
& \frac{\partial R\left(p_{H}, p_{L}\right)}{\partial p_{L}}-\left[\frac{\partial C_{H}\left(S_{H}, K_{H}\right)}{\partial K_{H}}-\frac{1}{\delta} \frac{\partial C_{H}\left(S_{H}, K_{H}\right)}{\partial S_{H}}\right] \frac{\partial K_{H}\left(p_{H}, p_{L}\right)}{\partial p_{L}}-\left[\frac{\partial C_{L}\left(S_{L}, K_{L}\right)}{\partial K_{L}}-\frac{1}{\delta} \frac{\partial C_{L}\left(S_{L}, K_{L}\right)}{\partial S_{L}}\right] \frac{\partial K_{L}\left(p_{H}, p_{L}\right)}{\partial p_{L}}=0
\end{aligned}
$$

Where $R$ denotes the total revenue obtained from selling both types of water to the two types of consumers. As in the textbook case, the profit-maximizing monopolist accounts for the reduction in marginal revenue caused by an extra unit sold in the market. Thus, $\frac{\partial R}{\partial K_{H}}<\frac{\partial V}{\partial K_{H}}$ and $\frac{\partial R}{\partial K_{L}}<\frac{\partial V}{\partial K_{L}}$ for all positive output levels $K_{H}, K_{L}$.

For $\delta=0$, the conditions in (7) become:

$$
\begin{aligned}
& \left.\frac{\partial C_{H}\left(S_{H}, K_{H}\right)}{\partial S_{H}}\right|_{\left(p_{H}, p_{L}\right)=\left(p_{H}^{m}, p_{L}^{m}\right)}=0 \\
& \left.\frac{\partial C_{L}\left(S_{L}, K_{L}\right)}{\partial S_{L}}\right|_{\left(p_{H}, p_{L}\right)=\left(p_{H}^{m}, p_{L}^{m}\right)}=0
\end{aligned}
$$

Given the parameters of our experiment, private monopoly profits are maximized for a supply of $\left(K_{H}=1, K_{L}=2\right)$, which occurs at prices $\left(p_{H}=392, p_{L}=167\right)$. Thus, the private monopolist is interested in restricting output and not letting the stocks fall below their maximum level. This implies that the private monopolist sells lower output and an even lower quality (due to a smaller participation of high quality water in the final mix) at prices that are higher than any of the price pairs implemented by the public utility. Furthermore, given that $K_{H}=1<a_{H}$ and, $K_{L}=2<a_{L}$, there is an excess of inflow which is systematically lost from the system, so aquifers are always at full capacity.

In the non-cooperative duopolistic management structure, equilibrium conditions become:

$$
\begin{gathered}
\frac{\partial R_{H}\left(p_{H}, p_{L}\right)}{\partial p_{H}}-\left[\frac{\partial C_{H}\left(S_{H}, K_{H}\right)}{\partial K_{H}}-\frac{1}{\delta} \frac{\partial C_{H}\left(S_{H}, K_{H}\right)}{\partial S_{H}}\right] \frac{\partial K_{H}\left(p_{H}, p_{L}\right)}{\partial p_{H}}=0 \\
\frac{\partial R_{L}\left(p_{H}, p_{L}\right)}{\partial p_{L}}-\left[\frac{\partial C_{L}\left(S_{L}, K_{L}\right)}{\partial K_{L}}-\frac{1}{\delta} \frac{\partial C_{L}\left(S_{L}, K_{L}\right)}{\partial S_{L}}\right] \frac{\partial K_{L}\left(p_{H}, p_{L}\right)}{\partial p_{L}}=0
\end{gathered}
$$

Where, $R_{H}$ and $R_{L}$ denote the two competing entities' revenues, respectively. This resembles the standard duopoly case. The left hand side in (9) fails to account for the 
pecuniary negative externality of each type of water on the profitability of the other. That is, while the private monopolist accounts for the effect of selling an extra unit of high quality water on the market price of low quality (and vice-versa), duopolists do not internalize the horizontal pecuniary externality. For $\delta=0$, the conditions in (9) become:

$$
\begin{aligned}
& \left.\frac{\partial C_{H}\left(S_{H}, K_{H}\right)}{\partial S_{H}}\right|_{\left(p_{H}, p_{L}\right)=\left(p_{H}^{B}, p_{L}^{B}\right)}=0 \\
& \left.\frac{\partial C_{L}\left(S_{L}, K_{L}\right)}{\partial S_{L}}\right|_{\left(p_{H}, p_{L}\right)=\left(p_{H}^{B}, p_{L}^{B}\right)}=0
\end{aligned}
$$

However, the duopoly equilibrium in pure strategies does not exist due to the discreteness of our setup and the possibility of simultaneously setting price and quantity. Nevertheless, intuitively, duopolistic prices and quantities will range between the corresponding magnitudes under private monopoly and the social planner's solution. To show this, we consider a unilateral deviation by the low-quality duopolist from the monopolistic equilibrium reported above. By decreasing the price-bid from 167 to 160 for the first 3 units, and then setting a prohibitively high price of, say, 1000 monetary units for the $4^{\text {th }}$ and $5^{\text {th }}$ unit of water, the duopolist increases its profits from 334 to 480 . The high quality duopolist also increases its profits from 392 to 400 , by reducing the price from 392 to 200, thus increasing its output from one to two units.

These deviations are not unique or optimal in any way, but they show that mixed price strategies will be below private monopoly prices and quantities will be above the private monopoly ones. In terms of stocks, given that these deviations yield consumption of less than 3 units for at least the low quality water, we cannot exclude the possibility that stocks in duopoly may be maximal and, thus, non distinguishable from stocks under private monopoly. We now consider duopolists' deviations from price/quantity schedules which implement the social first best. For example, prices of 50 for high and 30 for low quality water and limiting consumption to three units by prohibitively high prices for the $4^{\text {th }}$ and $5^{\text {th }}$ units of each resource, is one among many schemes implementing the first best solution. The high quality duopolist can raise its profit from 150 to 200 by unilaterally deviating from this scheme, if it restricts output to 1 unit and raises the price to 200. Similarly, the low quality duopolist will increase its profit from 90 to 100 units by raising its price from 30 to 50 and decreasing output from 3 to 2 units. 
We summarize our benchmark predictions for the parameters used in the experiment reported below:

- A public utility will set any price pair among many which implement the time-average quantities dictated by the hydrological equilibrium of 3 units from each resource, although this would be optimally achieved by alternating combinations $(4,2)$ and $(2,4)$ in subsequent periods. In a finite horizon context, reduction of stocks below the zero extraction cost level will take place towards the last periods.

- A private monopoly will keep stocks at maximum level and will sell 1 unit of the high quality and 2 units of the low quality water at prices 392 and 167, respectively. Due to this mix, quality will be lower than in the first best solution implemented by the public utility, and some resource will be lost due to under-extraction with respect to the hydrological equilibrium.

- Duopolists will set prices (sell outputs) below (above) private monopoly ones, while stocks will be (weakly) lower than maximum and higher than those under a public utility. Quality will also be lower than in the case of a public utility and weakly higher than under a private monopoly.

In terms of the observable magnitudes, the aforementioned predictions can be used to formulate the following testable hypotheses:

H1: Stocks will be maximal under a private monopoly and minimal towards the final periods under a public utility with a finite horizon, while duopoly stocks will range between these two extremes.

Apart from the predictions regarding the steady state stocks, we have a clear cut prediction regarding the outputs of the two types of water. The prediction stems from the fact that the hydrological equilibrium of the system implemented by the public utility requires that per period extraction levels must equal the rate of recharge of each resource. This is stated in the following testable hypothesis:

H2: Compared to the public utility, a private monopoly will significantly restrict output limiting the proportion of the high quality water in the mix consumed. Duopoly output ranges between these two extremes. 
Following these two predictions, quality-to-price ratios are expected to exhibit the following pattern:

H3: Quality-to-price ratios (prices) will be lower (higher) as we move from public management to duopoly and from duopoly to private monopoly.

Generally speaking, overconsumption of water is a rather extended problem in modern societies and it should be interesting to know whether, beyond natural scarcity, there are behavioural and institutional factors for the phenomenon to emerge even in abstract, initially non-scarcity involving situations like the ones implemented here.

\section{Experimental Design}

We experimentally tested the aforementioned hypotheses. All sessions were run in the Laboratori d'Economia Experimental at the Universitat Jaume I (Castellón, Spain) with undergraduate students in their final year of the BA in Business Administration. They knew the type of water resource they were managing, labelled as "low" or "high quality water". Subjects were told about the generic preference by consumers for high quality water over the low quality one. They also knew that the products were demand substitutes (though not perfect) and that the extraction costs were identical as specified in the written instructions provided to them (see Appendix B). The software designed specifically in our lab for the purpose of this experiment ${ }^{15}$ offered a simulator which calculated each unit's hypothetical costs and gains, in case the unit were actually consumed after markets cleared. ${ }^{16}$ They were also informed that the automated demand was programmed to react to price bids as a "smart" representative agent consuming and allocating quantities across consumer types in a way that maximizes total surplus. Thus, given each bidding schedule, consumer surplus maximization determined the quantity consumed for each quality. A history window displayed all past outcomes regarding own decisions, i.e. quantities, payoffs and market clearing prices.

\footnotetext{
${ }^{15}$ Distributed for research and training uses only, under the name "Hydromanagement", as freeware upon request from the authors.

${ }^{16}$ It is standard practice in experiments to give subjects a calculator that allows them to calculate their profits, given what others produce. The use of such a simulator provides them with a hypothetical exercise that forces them to think on the consequences of their actions as a response to others' strategies.
} 
Experimental markets lasted for 50 periods. In each period, subjects submitted five offer bids (minimum selling price) for each one of the first five units in their stocks for each one of the products they managed. All units of the same product were sold at the same market clearing price. All subjects were informed about how the market clearing price was determined.

Three different treatments were run. Table 1 below includes the details of the treatments. A number of learning rounds (not presented in the results) were run at the beginning of each session to familiarize the subjects with market conditions. Each session lasted on average 80 minutes. In all treatments, subjects were paid the sum of their profits in 15 randomly selected periods. Average earnings per subject were slightly below $25 €$. Duopoly sessions were more expensive as a higher exchange rate was used (see instructions in Appendix B) to avoid significant differences in individual subject rewards. Even though actual earnings depended on subject choices, this was done to avoid any extreme variations of expected per capita earnings across treatments. ${ }^{17}$

Table 1: Experimental design

\begin{tabular}{llccc}
\hline \multicolumn{1}{c}{ Treatment } & \multicolumn{1}{c}{ Decision makers } & $\begin{array}{c}\text { Sessions } \\
\text { (Periods) }\end{array}$ & $\begin{array}{c}\text { Subjects / } \\
\text { session }\end{array}$ & $\begin{array}{c}\text { Learning } \\
\text { rounds }\end{array}$ \\
\hline $\begin{array}{l}\text { Private } \\
\text { Monopoly }(\boldsymbol{T 1})\end{array}$ & $\begin{array}{l}\text { A single profit maximizing } \\
\text { monopolist. }\end{array}$ & $3(50)$ & 20 & Yes \\
\hline $\begin{array}{l}\text { Duopoly }(\boldsymbol{T} 2) \\
\text { Two independent profit } \\
\text { mabic }\end{array}$ & $\begin{array}{l}\text { Social welfare maximizing } \\
\text { Utility }(\boldsymbol{T} 3)\end{array}$ & $3(50)$ & 20 & Yes \\
\hline
\end{tabular}

Apart from the standard feedback received after each period in the monopoly treatments, in duopoly markets each subject observed also the clearing price at which the rival water quality was sold.

\footnotetext{
${ }^{17}$ Note that it is standard practice in experiments to avoid extreme earning inequalities across treatments. This is done to maintain incentives. This, however, does not affect results as exchange rates are the same within a treatment. See, for example, Rassenti et al. 2000 (p. 123).
} 


\section{Results}

Table 2 summarizes descriptive statistics for the two stocks, market clearing prices, quantities consumed and quality to price ratio. Statistics are provided for the whole experiment and the last 30 periods of it, in order to trace possible learning effects.

Table 2: Descriptive statistics for stocks, prices and quantities (by treatment)

\begin{tabular}{|c|c|c|c|c|c|c|}
\hline Variable & Firm & Treatment & Average & Std. Deviation & $\begin{array}{c}\text { Average } \\
\text { (periods 20-50) }\end{array}$ & $\begin{array}{c}\text { Std. Deviation } \\
\text { (periods 20-50) }\end{array}$ \\
\hline \multirow{6}{*}{ Quantity } & \multirow{3}{*}{ Low Quality } & $\mathrm{T} 1$ & 3.0 & 0.3 & 2.9 & 0.1 \\
\hline & & $\mathrm{T} 2$ & 3.0 & 0.2 & 2.9 & 0.2 \\
\hline & & $\mathrm{T} 3$ & 3.1 & 0.3 & 3.0 & 0.1 \\
\hline & \multirow{3}{*}{ High Quality } & $\mathrm{T} 1$ & 2.9 & 0.2 & 2.8 & 0.2 \\
\hline & & $\mathrm{T} 2$ & 3.0 & 0.3 & 2.9 & 0.1 \\
\hline & & $\mathrm{T} 3$ & 3.1 & 0.3 & 3.0 & 0.1 \\
\hline \multirow{6}{*}{ Price } & \multirow{3}{*}{ Low Quality } & $\mathrm{T} 1$ & 101.9 & 11.9 & 108.4 & 6.5 \\
\hline & & $\mathrm{T} 2$ & 69.8 & 5.2 & 72.2 & 3.6 \\
\hline & & $\mathrm{T} 3$ & 51.1 & 9.1 & 52.0 & 8.7 \\
\hline & \multirow{3}{*}{ High Quality } & $\mathrm{T} 1$ & 108.8 & 12.0 & 113.6 & 9.5 \\
\hline & & $\mathrm{T} 2$ & 75.7 & 8.1 & 80.0 & 5.3 \\
\hline & & $\mathrm{T} 3$ & 67.1 & 12.3 & 69.8 & 12.7 \\
\hline \multirow{6}{*}{ Stock } & \multirow{3}{*}{ Low Quality } & $\mathrm{T} 1$ & 11.4 & 1.2 & 10.9 & 0.3 \\
\hline & & $\mathrm{T} 2$ & 12.4 & 1.2 & 11.7 & 0.4 \\
\hline & & $\mathrm{T} 3$ & 9.5 & 1.7 & 8.7 & 0.5 \\
\hline & \multirow{3}{*}{ High Quality } & $\mathrm{T} 1$ & 12.7 & 1.1 & 12.2 & 0.4 \\
\hline & & $\mathrm{T} 2$ & 11.1 & 1.2 & 10.5 & 0.3 \\
\hline & & $\mathrm{T} 3$ & 9.3 & 1.9 & 8.3 & 0.7 \\
\hline \multirow{3}{*}{\multicolumn{2}{|c|}{ Average Quality/Price }} & $\mathrm{T} 1$ & 0.04 & 0.01 & 0.03 & 0.00 \\
\hline & & $\mathrm{T} 2$ & 0.04 & 0.01 & 0.04 & 0.00 \\
\hline & & $\mathrm{T} 3$ & 0.11 & 0.05 & 0.10 & 0.03 \\
\hline
\end{tabular}

The average quantity sold under a social planner (T3) is approximately equal to 3 units, which is compatible with the prediction in $\mathrm{H} 2$ concerning the hydrological equilibrium of the system, according to which the time average of consumption equals the rate of recharge. Furthermore, as predicted in H2, output under a private monopoly (T1) will be lower than this, while less high quality than low quality water will be sold in this structure. Finally, in duopoly (T2), output weakly lies between these two extremes, although the significance of these differences will be tested below using non parametric tests. In the same table we also observe that distinguishing between data 
from the whole session and data from the late rounds (20 to 50) shows that, probably due to learning, quantities sold get closer to the hydrological equilibrium over time. Further, the standard deviation in all treatments of quantities for both water qualities falls from between 0.20 and 0.30 to between 0.20 and 0.10 .

Within each treatment, average prices reflect qualities following the pattern of a higher price for a higher water quality. This resembles the usual result from vertical differentiation models in which equilibrium prices are ranked in the same way as product qualities. Furthermore, prices across treatments offer full support to the corresponding prediction in $\mathrm{H} 3$. That is, private monopoly prices are higher than duopoly ones, which, in their turn, are higher than prices under a social planner.

\subsection{Stock Levels}

Before proceeding with detailed analysis and hypothesis testing, we first plot (Figure 2) average stocks from all sessions of the Public Utility treatment. That is, we plot first aggregate data from sessions in which subjects were acting in the absence of strategic interaction and were rewarded according to overall levels of social welfare. We also plot the socially optimal path for the 50-period horizon of the experimental sessions. The figure also shows the observed and optimal paths for costs and social benefits, for the specific parameters implemented in the experiment. It can be seen that until period 31 , the social planner should keep stocks as close to maximal levels as possible, selling, first, 4 and 3 units of high and low quality water, respectively, and then alternating between outputs $(4,2)$ and $(2,4)$. From period 31 to 49 , the planner should follow a decreasing stock path, alternating between $(4,3)$ and $(3,4)$. Finally in the last period, (4, 4) are the socially optimal outputs, because $(5,5)$ is not an economically feasible combination due to the high extraction cost (50) from a stock level of 10.

Apparently, our subjects fail to realize the importance of keeping extraction costs at minimum levels by maintaining stock levels close to the maximum of 20 units throughout the first half of the session. Instead, they overexploited the resource starting from the early periods of the session, gaining an initial (periods 1-6 only) advantage over the theoretical path in terms of social benefits. However, as can be seen from comparison of the areas in which actual and optimal benefits have exceeded each other, overall observed profits have been significantly lower and costs higher than the optimum throughout the session. In fact, the initial periods in which more intense 
extraction yields higher profits than the optimal path, may be partly responsible for subjects' commitment to this erroneous pattern of behaviour.

From this first look at the stock dynamics observed in the case of the public utility, we can conjecture that, due to possible learning errors, decisions by human subjects in such a complex setting can generate suboptimal extraction patterns, even in the presence of the right incentives for a socially optimal management of the resources. Although hypothesis $\mathrm{H} 1$ is compatible with a decreasing trend of stocks after period 31 , the waste of the resource throughout the session is such that subjects would have been better off if they had raised stocks. It can be shown that a subject whose early errors lead stocks to an inefficiently low stock of, say, 7 units, would still find it profitable to restrict output and rise stocks even if the error is detected towards the $30^{\text {th }}$ or $40^{\text {th }}$ period. That is, the overall tendency to extract beyond the efficient levels cannot be explained as the result of early errors which become too costly to correct after a given number of periods, locking subjects into suboptimal paths.

What remains to be seen is whether the alternative market structures studied here can improve the situation through (i) a private, profit-oriented incentive mechanism, or (ii) a decentralized competitive market. It should be noted, that in the case of the private firm, the corresponding theoretical prediction foresees a deviation from the social optimum, as the private monopoly never finds it profitable to sell more than 1 unit of high and 2 units of low quality water, keeping stocks at maximal levels throughout the session and quality below that of the public utility. Thus, the loss of efficiency predicted is due to the exercise of market power leading to output restrictions and suboptimal output mix. 


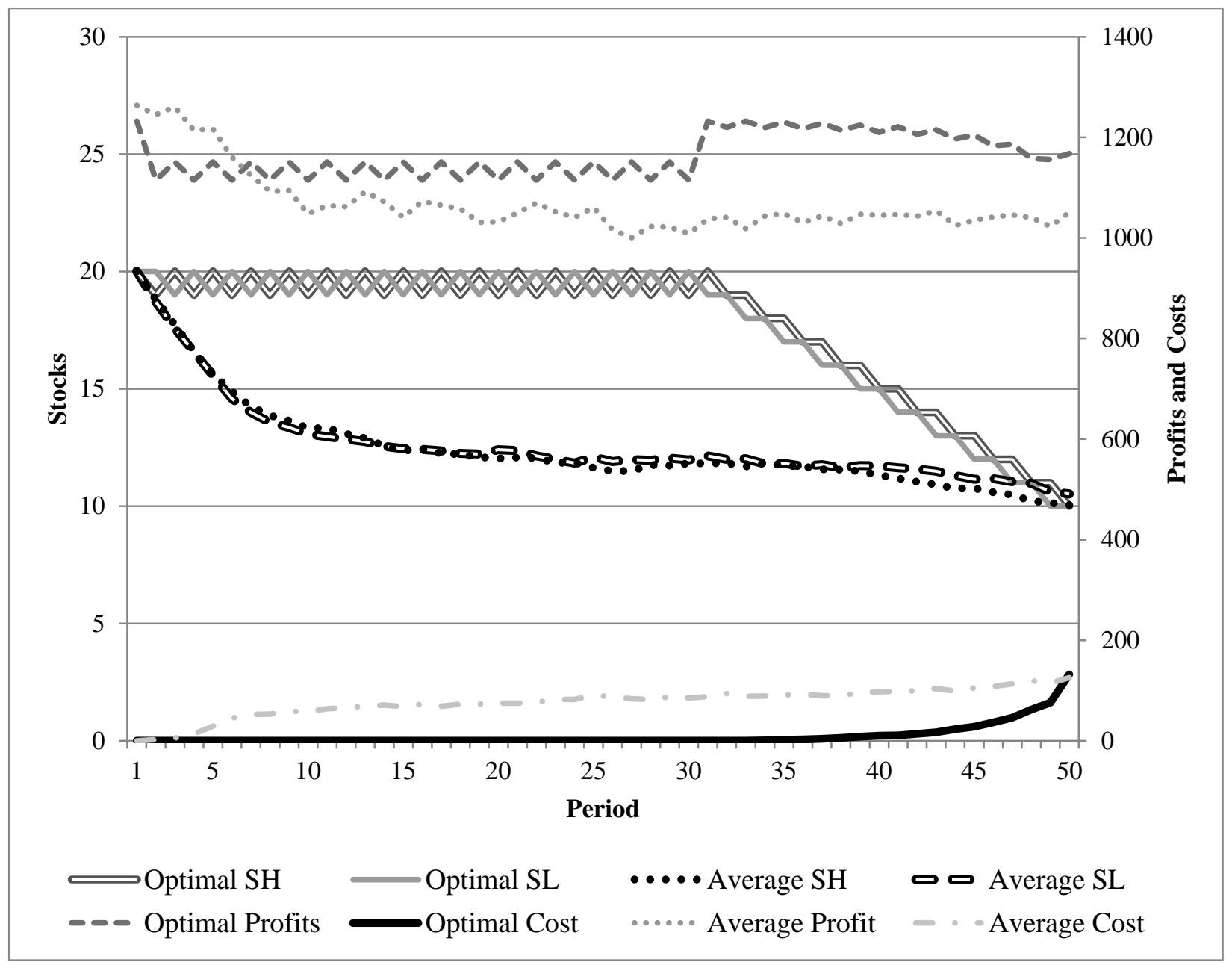

Figure 2. Optimal and observed stocks, profits and extraction costs for the public utility (T3)

The most interesting of our results regard hypothesis $\mathrm{H} 1$ on the management of stock levels. Table 2 shows differences in stock averages across treatments. In Table 3 we report results from non-parametrically testing the significance of these differences. It can be observed that all treatment differences in stocks are statistically significant at least at 5\%. In fact, all comparisons confirm H1, except for the difference in the low quality stocks across T1 and T2. Therefore, the prediction of higher stocks as we move from the public utility to duopoly and private monopoly is mostly supported.

Figures 3 and 4 compare water stock management across the three market structures. In each graph, the grey area corresponds to stock levels from which extraction would occur at no cost. As we have mentioned, stocks should remain within this area at least until period 31 for the public utility and throughout the session for the private monopolist. Contrary to this prediction, all treatments have led decision makers to extract from inefficiently low stocks. In fact, both stocks have been below the 
minimum efficient level in all treatments from very early periods $\left(5^{\text {th }}\right.$ period, the latest) of the experiment. This implies that due to purely behavioural reasons scarcity may occur even in the absence of exogenous restrictions in the availability of the resource.

Table 3: Stocks across treatments: Wilcoxon test statistic

\begin{tabular}{lllll} 
& \multicolumn{2}{l}{ Low Quality Stock } & \multicolumn{2}{l}{ High Quality Stock } \\
& $\mathbf{z}$ & $\mathbf{p}>|\mathbf{z}|$ & $\mathbf{z}$ & $\mathbf{p}>|\mathbf{z}|$ \\
\hline T1 = T2 & -6.393 & 0.000 & 6.384 & 0.000 \\
T1 = T3 & 6.342 & 0.000 & 6.359 & 0.000 \\
T3 = T2 & -6.384 & 0.000 & -6.307 & 0.000 \\
\hline
\end{tabular}

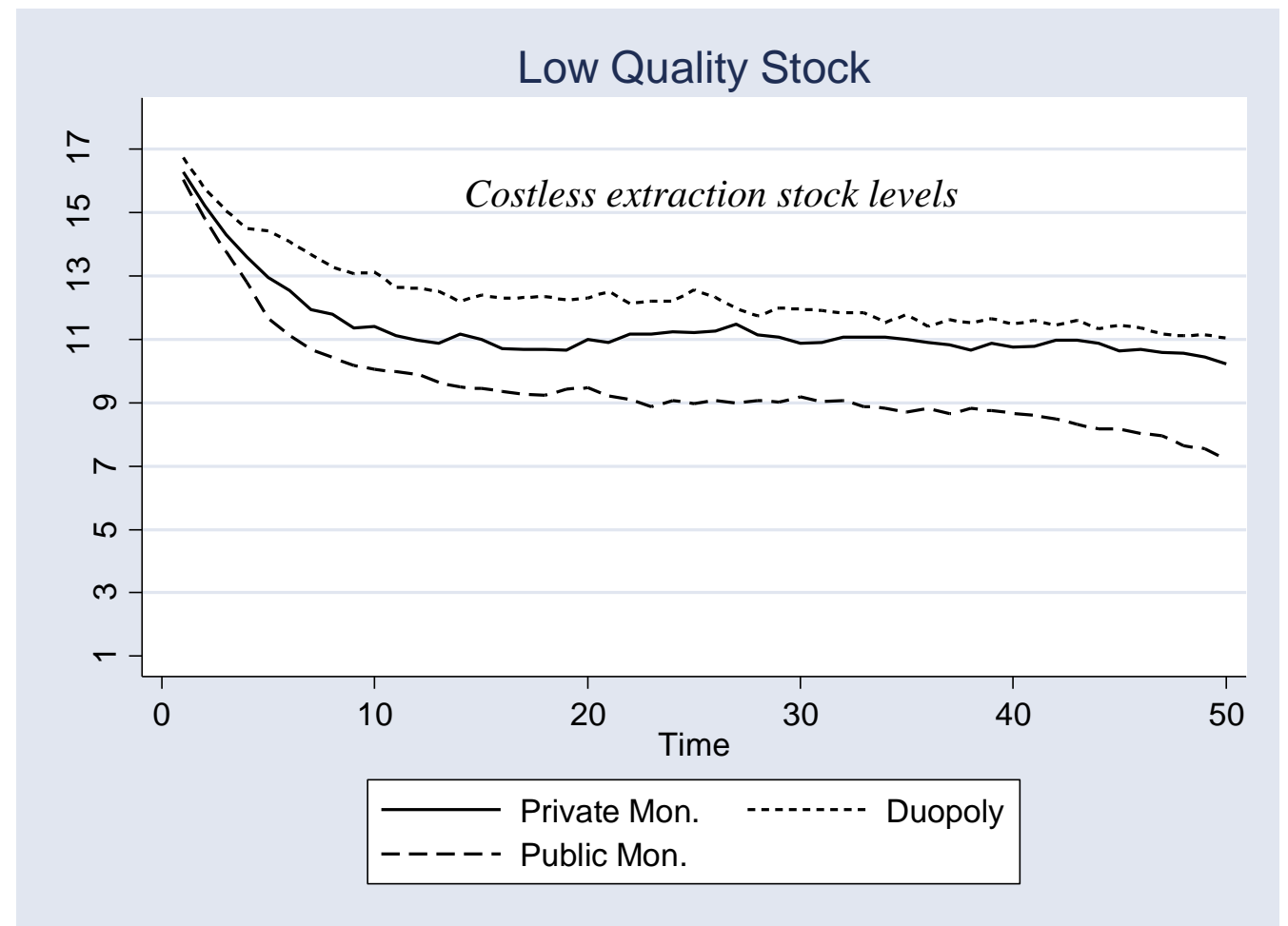

Figure 3. Evolution of experimental stocks (averages) of low quality water. 


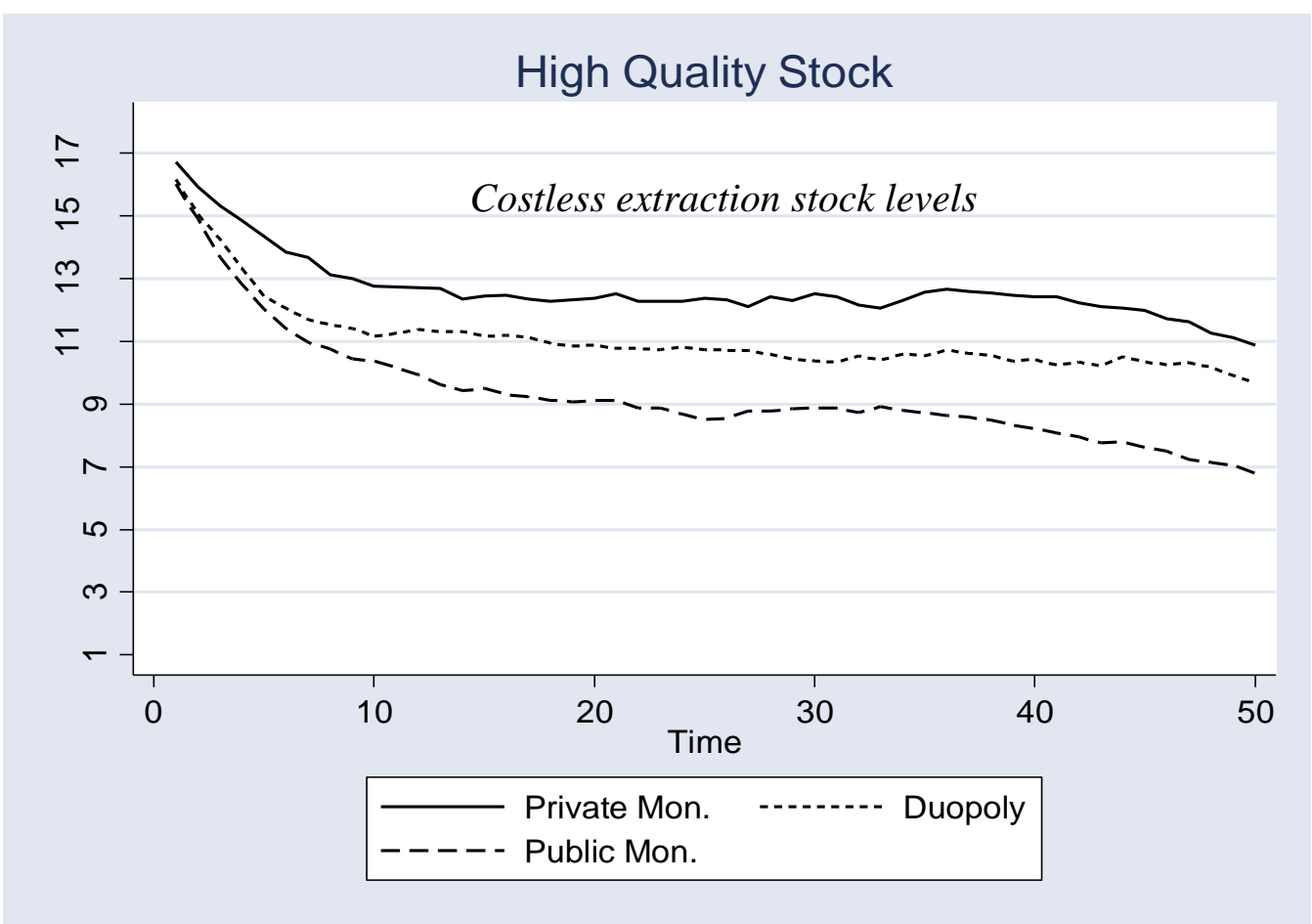

Figure 4. Evolution of experimental stocks (averages) of high quality water.

\subsection{Quantities sold}

Note that the prediction from $\mathrm{H} 2$ is that the quantities sold should be lower in the private than in the public utility case and that the latter should, on average, achieve and maintain the natural hydrological equilibrium $\left(K_{H}, K_{L}\right)=\left(a_{H}, a_{L}\right)=(3,3)$ until period 31 . Duopoly quantities should lie between these two benchmarks. As was already observed from the descriptive statistics on Table 2, Figures 5 and 6 show that the output chosen for the two qualities is close to 3 in all treatments, indicating the prevalence of the hydrological equilibrium over alternative rules. However, it is interesting to note that the output extracted by the public utility consistently lies above the output chosen by the private duopoly and private monopoly. Table 4 reports results obtained from a Wilcoxon test run to check the significance of these differences, confirming the prediction that the social planner will supply more water to the market than the private monopolist, while duopoly output will be between these benchmarks, except for the case of low quality water, in which output cannot be distinguished from that supplied by a private monopoly. 


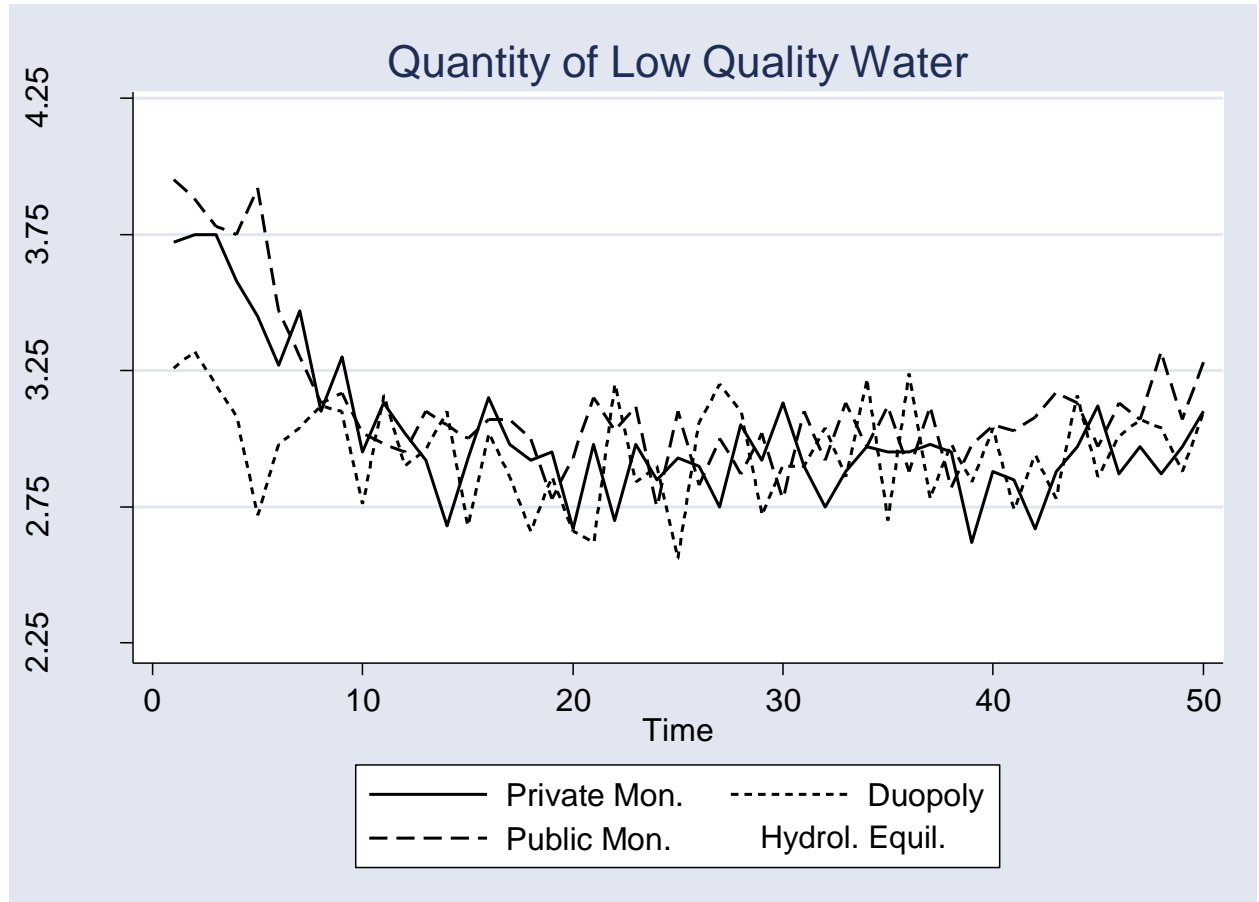

Figure 5. Experimental quantities (averages) of low quality water sold.

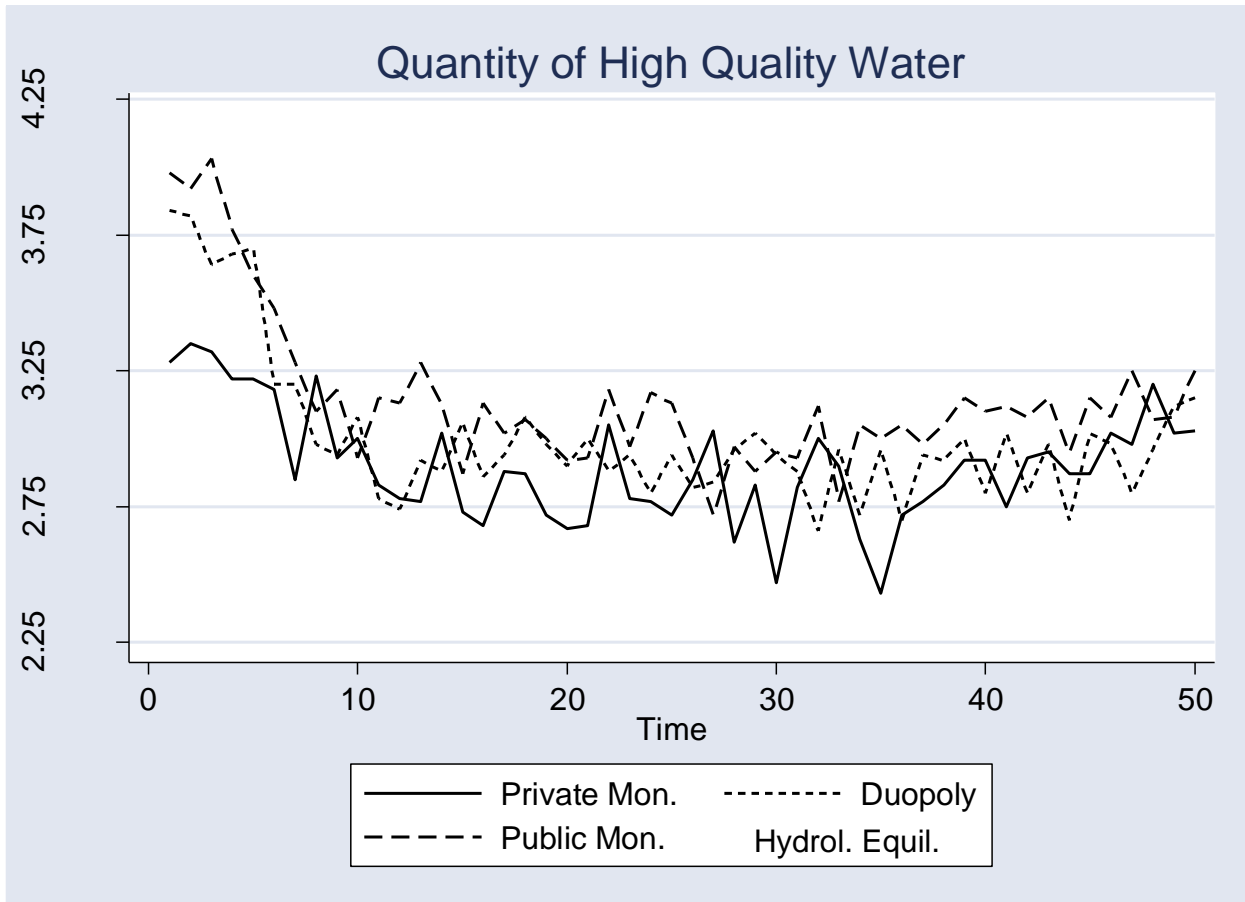

Figure 6. Experimental quantities (averages) of high quality water sold. 


\begin{tabular}{ccccc}
\hline & \multicolumn{2}{c}{ Quantity - Low $\mathbf{Q}$} & \multicolumn{2}{c}{ Quantity - High $\mathbf{Q}$} \\
& $\mathbf{z}$ & $\mathbf{p}>|\mathbf{z}|$ & $\mathbf{z}$ & $\mathbf{p}>|\mathbf{z}|$ \\
\hline T1 = T2 & 1.606 & 0.108 & -3.276 & 0.001 \\
T1 = T3 & -3.798 & 0.000 & -5.640 & 0.000 \\
T3 $=$ T2 & 3.720 & 0.000 & 4.619 & 0.000 \\
\hline
\end{tabular}

\subsection{Average quality to price ratio}

From the ranking of prices on Table 2 and the result on output levels, we expect that $\mathrm{H} 3$ is also confirmed. However, in order to directly test H3, we have to study treatment effects on the quality to price ratio.

Figure 7 presents the average quality/price ratio, $Q / P$, where $\bar{Q}$ is the average quality defined in expression (1), and $\bar{P}=\frac{K_{H} \cdot P_{H}+K_{L} \cdot P_{L}}{K_{H}+K_{L}}$. It is easy to see that the public monopoly provides the highest quality to price ratio relative to all other treatments. The average quality ratio provided by the duopoly is slightly above the private monopoly. A rather striking feature is the volatile pattern of the ratio obtained in the public monopoly treatment. This is in sharp contrast with the smooth patterns of the other two market structures. This difference can be understood taking into account that in this setup, the public monopolist receives more complex feedback that partly, but directly, depends on the consumer's social welfare. Specifically, the consumer's loss associated with the cost of purification, in case the quality falls below the "potable" threshold, negatively affects the feedback received by subjects on the success of their strategies. Volatility arises due to the continuous effort by subjects (each one representing the social planner) to cope with the additional objective of maintaining quality above a certain level (in order not to trigger the costly, thus inefficient, purification procedure).

Table 5 below presents the Wilcoxon t-test values for the comparison between average quality/price levels across the three market structures. Average quality to price is statistically different across all three treatments in the way predicted by $\mathrm{H} 3$, according to which price to quality ratio increases as we move from private monopoly to duopoly and public utility. 


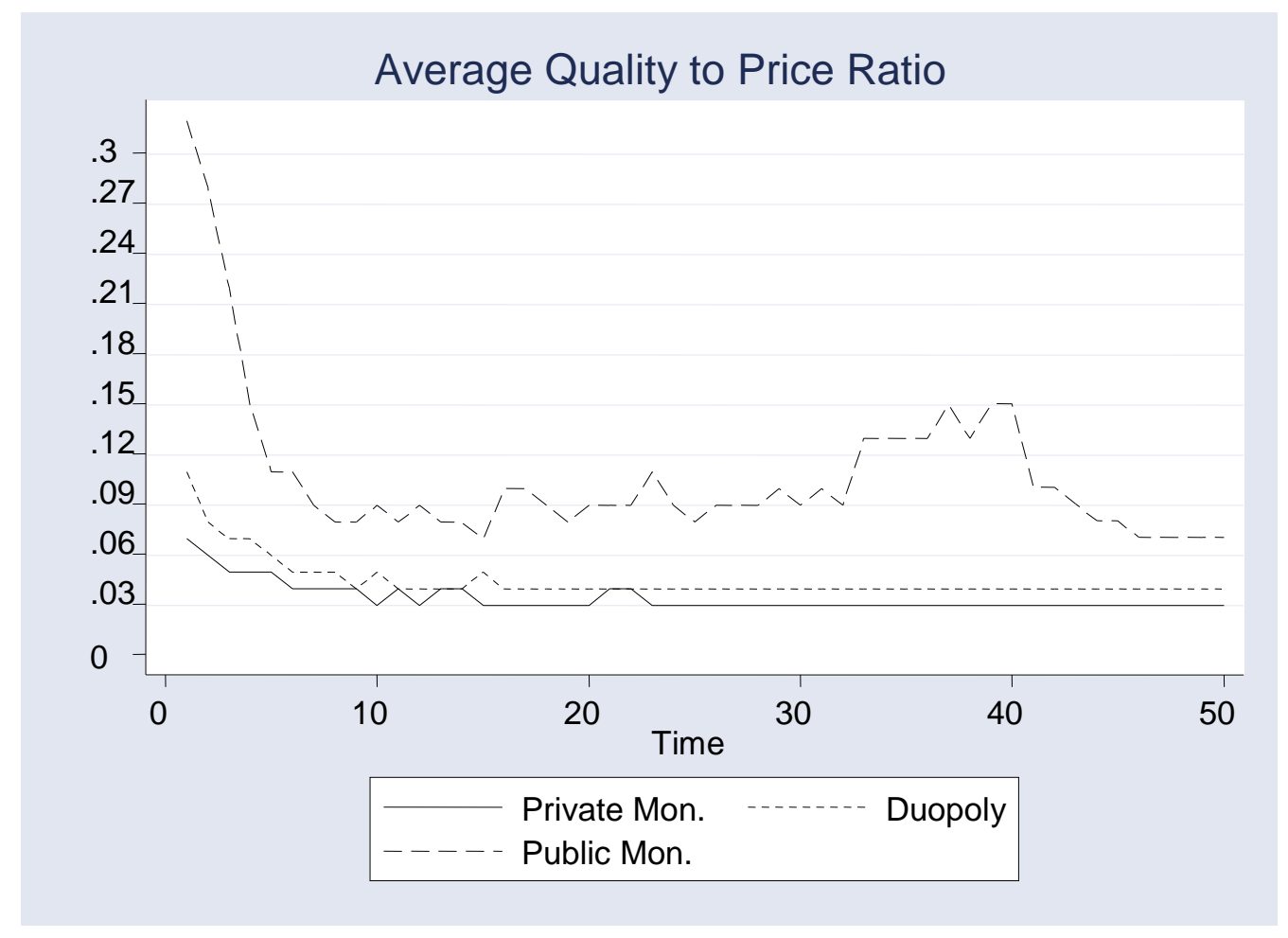

Figure 7. Evolution of quality-to-price ratio (averages).

Table 5. Average Quality/Price ratio:

Wilcoxon test statistic across treatments

\begin{tabular}{ccc}
\hline & & \\
& $\mathbf{z}$ & $\mathbf{p}>|\mathbf{z}|$ \\
\hline $\mathbf{T 1}=\mathbf{T 2}$ & -6.393 & 0.000 \\
$\mathbf{T 1}=\mathbf{T 3}$ & -6.393 & 0.000 \\
$\mathbf{T 3}=\mathbf{T 2}$ & 6.393 & 0.000 \\
\hline
\end{tabular}

\section{Conclusions}

In this paper we provide the first experimental attempt at studying water management of two different water resources endogenously determining the quality of water supplied by a public utility, a private monopoly and a duopoly to consumers who differ in their preferences on quality. Our structure is inspired by the problem of growing importance in many countries regarding the level of disaggregation of decision making and management of national, or regional, aquifers. In terms of extraction efficiency, public management is both theoretically and empirically shown to be the least successful of the 
structures considered, although it is the most successful one in achieving the highest quality to price ratios.

Our experiments identify a purely behavioural foundation of resource overexploitation. That is, rather than natural scarcity or wrong institutional design, water over-exploitation may be due to human decision errors which persist even after a large number of periods of learning from past actions and feedback. Unfortunately, according to our results, this type of error cannot be avoided by any market institution alone, although management by a social planner exacerbates this behavioural bias as compared to a private duopoly or monopoly. As said already, this shortcoming of public management must be compared with the advantage of a higher water quality supplied to the consumers, given that the social planner is more generous with the high quality contained in its quality mix. Our experimental results suggest that, rather than the degree of centralization of the decision making process, what really matters is the market institution providing decision makers with different incentives.

An interesting implication of our setup is that block rate pricing and the overall market clearing mechanism used here are useful in allocating water resources even in the case of a public utility. On the contrary, learning from trial and error is not sufficient for our subjects to find the optimal extraction path, despite their ability to figure out and implement the hydrological equilibrium of the system. In this respect, the difference between the public and the private monopoly scenarios is that the former faces a more complex problem than the latter does. While the public utility receives feedback on both revenues and consumer surplus, the private monopolist receives feedback on own profits and is adjusting strategies accordingly. In fact, incentives for the public utility are such that subjects post their bids aiming at simultaneously satisfying the condition for the hydrological equilibrium of the system and, at the same time, keeping water quality high. Whether the complexity of the problem and the resulting feedback induce a persistent learning shortcoming or not is not answered by our results so far. Thus, useful extensions of the experiments presented here would be to allow for longer sessions, more informative feedback and even a smart agent assisting subjects on the supply side. Future research should also focus on the effect of increasing the number of firms, and introducing competitive extraction from a common pool. 
Acknowledgements. We are particularly indebted to the editor and two anonymous referees for an exceptionally fruitful review process which has substantially improved this paper. We gratefully acknowledge financial support by the Spanish Ministry of Science and Technology (ECO2008-00977/ECON and ECO2008-04636/ECON), Junta de Andalucía (P07-SEJ-03155), Bancaixa (P1-1B2010-17), Instituto Universitario de Economía, Consolider-Ingenio 2010 and the Comunidad de Madrid (Excelecon), as well comments received by seminar participants at Univ. Massachusetts Amherst. 


\section{References}

Bell R, Beare S (2000) Salinity targets in the Murray Darling Basin. Australian Commodities 7(2): 348-356.

Bjornlund H, McKay J (1998) Factors affecting water prices in a rural water market: a south Australian experience. Water Resources Research 34(6):1563-1570.

Bjornlund H (2003) Efficient water market mechanisms to cope with water scarcity. Water Resources Development 19(4): 553-567.

Calatrava J, Garrido A (2006) Water markets and customary allocation rules: explaining some of the difficulties of designing formal trading rules. Journal of Economic Issues XL(1): 27-44.

Diao X, Roe T (2003) Can a water market avert the "double-whammy" of trade reform and lead to a "win-win" outcome? Journal of Environmental Economics and Management 45: 708-723.

Dinar A, Letey J (1991) Agricultural water marketing, allocative efficiency and drainage reduction. Journal of Environmental Economics and Management 20: 210233.

García-Gallego A, Georgantzís N (2009) Market effects of changes in consumers' social responsibility. Journal of Economics and Management Strategy 18: $235-262$.

Gardner R, Moore, MR, Walker JM (1997) Governing a groundwater commons: A strategic and laboratory analysis of western law. Economic Inquiry 35: 218-234.

Garrido A (2007) Water markets design and evidence from experimental economics. Environmental and Resource Economics 38: 311-330.

Gjerstad S, Williams A, Smith VL, Ledyard JO (2000) Concurrent trading in two experimental markets with demand interdependence. Economic Theory 16: 511528.

Gómez-Ramos A, Garrido A (2004) Formal risk-sharing mechanisms to allocate uncertain water resources: The case of option contracts. Water Resources Research 40, W12302. DOI:10.1029/2004WR003340.

Gordon HS (1954) The economic theory of a common property resource: The fishery. Journal of Political Economy 62: 124-142.

Hearne RE, Easter RR (1998) Economic and financial returns from Chile's water markets. In: Easter KW, Rosegrant MW, Dinar A (eds) Markets for water: potential and performance. Kluwer Academic Publishers, New York, pp159-172. 
Mason CF, Phillips OR (1997) Mitigating the tragedy of the commons through cooperation: An experimental evaluation. Journal of Environmental Economics and Management 34:148-172.

McCabe KA, Rassenti SJ, Smith VL (1989) Designing 'smart' computer assisted markets in an experimental auction for gas networks. European Journal of Political Economy 5: 259-283.

McCabe KA, Rassenti SJ, Smith VL (1991) Smart computer assisted markets. Science 254: 534-538.

Moench M (1992) Chasing the water table: Equity and sustainability in groundwater management. Economic and Political Weekly 27 (51-52): A171-A177.

Murphy JJ, Dinar A, Howitt RE, Rassenti SJ, Smith VL (2000) The design of smart water market institutions using laboratory experiments. Environmental and Resource Economics 17: 375-394.

Murphy JJ, Dinar A, Howitt RE, Rassenti SJ, Smith VL, Weinberg M (2009) The design of water markets when instream flows have value. Journal of Environmental Management 90: 1089-1096.

Mussa M, Rosen S (1978) Monopoly and product quality. Journal of Economic Theory 18: 301-317.

Olmstead J, Sunding D, Parker D, Howitt R, Zilberman D (1997) Water Marketing in the '90s: Entering the electronic age. Choices (Third Quarter): 24-28.

Rassenti S, Reynolds SS, Smith VL, Szidarovszky F (2000) Adaptation and convergence of behavior in repeated experimental Cournot games. Journal of Economic Behavior and Organization 41: 117-146.

Shaked A, Sutton J (1982) Relaxing price competition through product differentiation. Review of Economic Studies 49: 3-14.

Shubik M (1974) A trading model to avoid tatônnementmetal physics. Cowles Foundation disc. pap. No. 368.

Smith VL (1976) Induced Value Theory, American Economic Review-Papers and Proceedings 66 (2): 274-279.

Walker JM, Gardner R, Ostrom E (1990) Rent dissipation in limited access common pool resource environments: Experimental evidence. Journal of Environmental Economics and Management 19: 203-211.

Walker JM, Gardner R (1992) Probabilistic destruction of common-pool resources: Experimental evidence. The Economic Journal 102: 1149-1161. 
Weinberg MC, King CL, Wilen JE (1993) Water markets and water quality. American Journal of Agricultural Economics 75(2): 278-291.

World Bank (1993) Water resources management: A World Bank policy paper. Washington D.C.

World Pumps (2008) Water and wastewater. Growing water services in a worldwide market. World Pumps correspondent Hans-Jürgen Bittermann reports. May 2008.

Yang H, Zhang X, Zehnder AJB (2003) Water scarcity, pricing mechanism and institutional reform in Northern China irrigated agriculture. Agricultural Water Management 61, 143-161. 


\section{Appendix}

\subsection{Appendix A: Mathematical model}

We provide here the specific mathematical expressions used here to implement the model outlined in the main text. The household's instantaneous utility is given by the following function:

$U^{h}\left(K_{H h}, K_{L h}, Q_{M h}\right)=205 \cdot \ln \left[1+\left(\max \left\{Q_{\min }, Q_{M h}\right\}+\left(K_{L h}+K_{H h}\right)\right) \cdot\left(K_{L h}+K_{H h}\right)-C_{\Delta Q_{h}}\right\rfloor$,

where the last term in brackets denotes the purification costs:

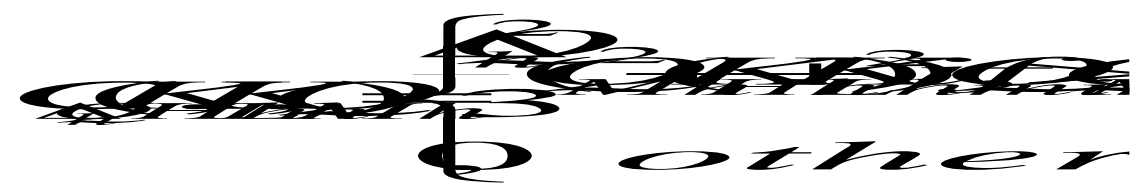

The farmer's instantaneous utility is given by:

$$
U^{f}\left(K_{H f}, K_{L f}, Q_{M f}\right)=170 \cdot \ln \left[1+0.5 \cdot\left(Q_{M f}+3 \cdot\left(K_{L f}+K_{H f}\right)\right) \cdot\left(K_{L f}+K_{H f}\right)\right]
$$

Resource $i$ 's $(i=H, L)$ extraction costs of $K_{i}$ units from a given stock level $S_{i}$ is denoted by $C_{i}\left(S_{i}, K_{i}\right)$. For the discrete case implemented here, this information is summarized in the Table of extraction costs in Appendix B below. Also, in the discrete version here, household and farmer utilities from the consumption of all possible combinations between zero and five units are summarized in the following table:

\begin{tabular}{|c|c|c|c|c|c|c|}
\hline household & Low 0 & 1 & 2 & 3 & 4 & 5 \\
\hline High 0 & 0 & 174 & 301 & 356 & 378 & 378 \\
\hline 1 & 399 & 492 & 579 & 637 & 679 & 711 \\
\hline 2 & 555 & 624 & 690 & 753 & 797 & 832 \\
\hline 3 & 660 & 717 & 771 & 822 & 869 & 906 \\
\hline 4 & 740 & 789 & 836 & 880 & 920 & 959 \\
\hline 5 & 806 & 849 & 890 & 929 & 965 & 999 \\
\hline
\end{tabular}

\begin{tabular}{|c|c|c|c|c|c|c|}
\hline farmer & Low 0 & 1 & 2 & 3 & 4 & 5 \\
\hline High 0 & 0 & 187 & 354 & 471 & 560 & 631 \\
\hline 1 & 274 & 391 & 491 & 572 & 639 & 696 \\
\hline 2 & 422 & 509 & 584 & 647 & 702 & 749 \\
\hline 3 & 525 & 594 & 655 & 707 & 753 & 794 \\
\hline 4 & 604 & 662 & 712 & 757 & 798 & 834 \\
\hline 5 & 668 & 717 & 761 & 801 & 836 & 869 \\
\hline
\end{tabular}




\subsection{Appendix B: Instructions to subjects}

\section{Treatments 1, 2 and 3}

The aim of this experiment is to study how people make their decisions in certain contexts. Your decisions, in the scenario explained below in detail, will be directly related to a monetary reward you will receive in cash at the end of the experiment. Any doubt you may have will be clarified personally (to you) by one of the organizers after you raise your hand. Beyond these questions, any other communication is strictly forbidden and is subject to immediate exclusion from the experiment.

You participate in a market that is characterized by the following features:

- You are the only producer of two commodities: product $H$ and product L. [Treatment 2: There are two producers (1 and 2) and two commodities (product $\mathrm{H}$ and product L)]. [Treatment 3: You represent a social planner who produces two commodities: product $H$ and product L.] Specifically, product $H$ is water of High quality, while product $L$ is water of Low quality. Products $H$ and $L$ are substitutes, namely, consumers may, to a certain extent, substitute one type of water with the other.

- Treatment 2: You are one of the two producers in this market. At the beginning of the session, the computer will indicate if you are producer 1 or 2 . Your competitor will be one (always the same) of the subjects in this room, randomly selected by the computer when the session starts.

- There are two types of consumers: households and farmers. Although they have different preferences with respect to the two types of water, they all prefer water of high quality (product $H$ ) to water of low quality (product $L$ ). That is, they are willing to pay more for $H$ than for $L$.

- The market will last for 50 rounds.

\section{Decision Making}

Your only decision as a producer is announcing the minimum price at which you are willing to sell each one from a maximum of 5 units you may sell for each product. Such announcements of minimum prices are called price bids. In order to make your decisions, you have to take into account that:

1. The extraction cost per additional unit extracted and by product is included in the "table of costs" below. These costs are the same for the two products [Treatment 2: (therefore, costs conditions for you and your competitor are identical)], and they are expressed in ExCUs, a fictitious Experimental Currency Unit. 
2. Taking into account the costs of the table, you have to announce five minimum prices at which you are willing to sell each unit of the five units of each [Treatment 2: your] product you may sell in each product. Therefore, your decision making process consists of fixing 5 price bids for each [Treatment 2: your] product.

3. You should have in mind that, in order not to make any losses, price bids cannot be lower than the corresponding unit costs included in the table of costs.

4. Price bids cannot be decreasing. That is, your bid for the $1^{\text {st }}$ unit cannot be higher than your bid for the $2^{\text {nd }}$ unit; the bid for the $2^{\text {nd }}$ cannot be higher than the bid for the $3^{\text {rd }}$ unit, and so on and so forth.

5. Observe in the table that the unit costs decrease with the stock size. At the beginning of the session, you have an initial stock size of 20 units [Treatments 1 and 3: for each product]. At the beginning of each round, you get three more units [Treatments 1 and 3: for each type of water].

6. Your stock size [Treatments 1 and 3: for each type of water] can never exceed 20 units and, therefore, once 20 units are reached, any additional units you may receive are lost.

\begin{tabular}{|l|c|c|c|c|c|c|c|c|c|c|}
\hline Stock size & $\mathbf{2 0}$ & $\mathbf{1 9}$ & $\mathbf{1 8}$ & $\mathbf{1 7}$ & $\mathbf{1 6}$ & $\mathbf{1 5}$ & $\mathbf{1 4}$ & $\mathbf{1 3}$ & $\mathbf{1 2}$ & $\mathbf{1 1}$ \\
\hline Unit cost & 0 & 0 & 0 & 0 & 0 & 1 & 1 & 2 & 2 & 4 \\
\hline & & & & & & & & & & \\
\hline Stock size & $\mathbf{1 0}$ & $\mathbf{9}$ & $\mathbf{8}$ & $\mathbf{7}$ & $\mathbf{6}$ & $\mathbf{5}$ & $\mathbf{4}$ & $\mathbf{3}$ & $\mathbf{2}$ & $\mathbf{1}$ \\
\hline Unit cost & 7 & 11 & 18 & 30 & 50 & 82 & 135 & 223 & 368 & 607 \\
\hline
\end{tabular}

Table of extraction costs (expressed in ExCUs)

\section{Example}

Suppose that at the end of a round your stock size [Treatments 1 and 3: of one of your products] is 9 units. At the beginning of the new round, you get your additional 3 units (so that your stock now is 12 units). Observe in the table that, for a stock size of 12 units, the unit cost for the first five units extracted is the following:

- the cost of the 1st unit: 2 ExCUs

- the cost of the 2nd unit: 4 ExCUs

- the cost of the 3rd unit: 7 ExCUs

- the cost of the 4th unit: 11 ExCUs

- the cost of the 5th unit: 18 ExCUs 
In order not to make losses, each one of your bids should not be lower than the corresponding unit cost. Therefore, in this example, your bid for the $1^{\text {st }}$ unit should not be lower than 2 ExCUs (cost of the $1^{\text {st }}$ unit); your bid for the $2^{\text {nd }}$ unit should not be lower than neither 4 ExCUs (cost of this unit) nor your bid for the $1^{\text {st }}$ unit; your bid for the $3^{\text {rd }}$ unit should not be lower than neither 7 ExCUs nor your bid for the $2^{\text {nd }}$ unit, and so on for the rest of the units.

In case you sell 5 units [Treatments 1 and 3: of this product], the stock size at the beginning of next round would be 10 units (7 you kept plus 3 you get in the new round). If, given your bids for the five units, your sales are zero, your stock would be 15 units (12 you already had plus 3 you get at the beginning of the round).

\section{Decisions}

- You make decisions on the minimum price at which you are willing to sell each unit of each one of the two products [Treatment 2: of your product]. You will fill in all the boxes that appear at your computer screen with your price bids [Treatments 1 and 3: (5 bids for product $H$ and 5 for product $L$ )]. In each box, you will also get information related to the corresponding unit cost. The bids you submit have to be integer numbers between zero and 2000.

- Although you may propose five different price bids, all units of the same product will be sold to consumers at a single price. This price will be your bid for the "last" unit sold of each product. The number of units sold each period is calculated by a program that simulates the optimal behaviour of consumers.

\section{Example}

In the example above, assume that your bids for [Treatment 2: your product] one of the products are: 10 (for the $1^{\text {st }}$ unit), 12 (for the $2^{\text {nd }}$ ), 14 (for the $3^{\text {rd }}$ ), 16 (for the $4^{\text {th }}$ ) and 20 (for the $5^{\text {th }}$ ). Given your bids, the program that simulates the optimal behaviour of consumers, determines that 3 units of this product will be sold. The price at which you will sell the three units will be your bid for the 3rd unit, that is, 14 ExCUs.

\section{Only Treatments 1 and 2: The profits}

- Your net profit of selling each unit of a product will be the difference between the market price at which you sold all units [Treatment 1: of that specific product] (your unit income) and the corresponding unit extraction cost. Total profits will be the sum of the unit profits for all periods.

\section{Example}


Taking again the previous example, if, at the beginning of a round, your stock size is 12 units, your total profits in that round will be 29 ExCUs, which are decomposed as follows:

i) 12 ExCUs for the 1st unit sold (14 ExCUs you receive for that unit minus 2 ExCUs it costs you extracting it).

ii) 10 ExCUs for the $2^{\text {nd }}$ unit sold (14 ExCUs you receive for that unit minus 4 ExCUs it costs you extracting it).

iii) 7 ExCUs for the 3rd unit sold (14 ExCUs you receive for that unit minus 7 ExCUs it costs you extracting it).

\section{Only Treatment 3: The aim}

- As a social planner, your aim in each round is to maximize the social benefit per unit sold in this market, which is defined as the difference between the utility level generated by each unit consumed and the corresponding unit extraction cost.

\section{The information}

- During decision making, the computer will provide you with a table simulating results [Treatment 1: (for each product)], conditional to your bid and cost for the corresponding unit in five possible scenarios: $a$ ) In case you only sell the $1^{\text {st }}$ unit; $b$ ) If you just sell the first two units; ...e) In case you sell 5 units.

- Only Treatment 3: At the beginning of each round, the computer will provide you with a table containing, conditional to the stock size for each type of water and all possible combinations of consumption of the two products, the corresponding social benefits (measured as the difference between the utility level and corresponding extraction costs) of that round.

- At the end of each round, the computer screen will show you the total profits [Treatment 3: social benefits] obtained in that round, including information about unit cost, market price and number of units sold of each product, [Treatment 2: as well as your rival's price].

- During the experiment, you will be provided with a screen containing the history of past rounds (market price for each product, number of units sold, [Treatments 1 and 3: of each product], [Treatments 1 and 2: total revenue and total profits [Treatment 1: per product]], [Treatment 3: and social benefit]).

\section{Monetary reward}

- Your monetary reward at the end of the session will be the sum of your profits accumulated in 15 rounds (randomly selected by the computer) of the total of 50 rounds, at an equivalence rate of 800 ExCUs=1 Euro [Treatment 2: 500 ExCUs=1 Euro]. You will be paid in cash at the end of the session. 
In order to make sure you understood correctly the market described above, we will proceed next to run a pilot session of 5 rounds. Please, feel free to make any questions you may have during this pilot session.

Thank you for your collaboration. Good luck! 